\section{Molecular Genotyping of Human Influenza Viruses in Central Greece during the Period 2012-2014 and Vaccine Strain Match}

\section{Abstract}

Title: Molecular Genotyping of Human Influenza Viruses in Central Greece during the Period 2012-2014 and Vaccine Strain Match Molecular Genotyping of Human Influenza Viruses in Central Greece during the Period 2012-2014 and Vaccine Strain Match.

Background: Influenza virus activity can cause significant burden to the community, associated with increased morbidity and mortality due to complications from influenza illness. This is the first preliminary study of influenza virus molecular epidemiology in central Greece.

Methods and findings: In central Greece, during the period 2012-2014, from October-April each year, influenza A (H1N1) and A (H3N2) viruses were detected and were the dominant viral subtypes associated with influenza illness. A total of 865 respiratory samples were screened by real-time RT-PCR during the two seasons and $9 \%$ and $12 \%$ of influenza $A(H 1 N 1)$ and $A(H 3 N 2)$ viral genotypes were detected, respectively. Influenza activity was markedly increased in the 2013-2014, as compared to the 2012-2013 season, with the detection of A (H1N1) pdm09 viruses along with $A(H 3 N 2)$ and $B$ viruses. All $A(H 1 N 1), A(H 3 N 2)$ and $B$ influenza viral isolates analyzed showed similarity to vaccine-like viruses of the same period, both antigenically and genetically.

Conclusions: Our findings from this preliminary study underline the importance for laboratory surveillance of influenza activity in the community and its contribution to improved influenza illness management and influenza vaccine formulation.

Keywords: Influenza viruses; Central Greece; Influenza vaccine

\section{Vontas A, Plakokefalos E, Krikelis V and Manouras A \\ Department of Medical Laboratories, Technological Educational Institute of Thessaly 41222, Larissa, Greece}

\section{Corresponding author:}

Plakokefalos E

” eplako@teilar.gr

Department of Medical Laboratories, Technological Educational Institute of Thessaly 41222, Larissa, Greece.

Citation: Vontas A, Plakokefalos E, Krikelis V, et al. Molecular Genotyping of Human Influenza Viruses in Central Greece during the Period 2012-2014 and Vaccine Strain Match. J Infec Dis Treat. 2016, 1:1.

Received: October 21, 2015; Accepted: December 26, 2016; Published: December 28, 2016

\section{Introduction}

Influenza viruses belong to the Orthomyxoviridae family, contain a segmented RNA genome of negative polarity and are classified into three distinct types. Type A viruses infect a variety of animal species including humans and are divided into subtypes based on antigenic characteristics of their hemagglutinin (HA) and neuraminidase (NA) surface glycoproteins [1-3]. Currently, there are identified 16 and 9 subtypes of $\mathrm{HA}$ and NA, respectively. All subtype combinations are found in wild aquatic birds which serve as natural reservoirs of novel influenza viral strains which arise via genetic reassortment events [4,5]. Type A viruses have frequently been associated with yearly epidemic episodes due to higher rate of mutation in their HA and NA molecules [3]. Type B and $C$ viruses infect mainly humans, while the latter cause mild symptoms mainly in children and young adults [2].

Influenza A and B viruses constitute significant respiratory pathogens which are transmitted mainly by droplets and aerosols originating from the respiratory secretions of infected people. Each year influenza and complications that result from infection account for increased indices of morbidity and mortality worldwide, especially among individuals belonging to the highrisk groups. Yearly vaccination with the trivalent influenza vaccine is recommended at the beginning of the influenza season in order to reduce the impact of the disease in the community [6]. Laboratory 
surveillance of influenza viruses provides valuable information on the pathogenic profile of circulating viral strains [7, 8]. Realtime quantitative RT-PCR protocols are among the most widely used methods in the diagnosis of influenza infection since they are performed to screen large number of samples with maximum sensitivity and specificity even when viral antigens are destroyed [912]. Moreover, rt-RT-PCR has been evaluated during seasonal and pandemic influenza activity in influenza diagnosis and surveillance laboratories [13]. In the present study, we report the preliminary laboratory data relating to influenza virus molecular epidemiology in central Greece during the period 2012-2014.

\section{Methods}

\section{Clinical specimen}

During the period 2012-2014, from October-Aprileach year, a total of 865 nasal and pharyngeal swabs were collected from non-vaccinated individuals of all ages presenting with influenza-like illness (ILI), 3-4 days following the onset of symptoms. Sampling took place during the influenza season in Greece from December to April, by health professionals at the University Hospital and by physicians of the sentinel network in Larissa, Thessaly, Greece.Sample storage and transport was accomplished in virus transport medium $(24,9 \mathrm{gr}$ bacto-tryptose, 5 gr gelatin, 0,5 gr streptomycin, 500,000 $U$ penicilin and $50 \mathrm{mg}$ fungizone) per liter. Storage was at $+4^{\circ} \mathrm{C}$ for up to 4 days. Long-term storage of the clinical samples was at $-70^{\circ} \mathrm{C}$.Symptoms included high fever $\left(>39^{\circ} \mathrm{C}\right)$, myalgia, cough, headache, malaise, and in certain cases there was recorded complications, mainly secondary bacterial pneumonia.

\section{Real-time RT-PCR (rt-RT-PCR)}

Total RNA was extracted from $200 \mathrm{ml}$ of processed clinical sample with TRIzol (Gibco BRL, Life Technologies, NY, USA), according to manufacturer's recommendations, in the presence of $20 \mathrm{mg}$ glycogen, molecular biology grade (Boehringer, Germany). Reactions in real-time RT-PCR were performed in a 7500 Applied Biosystemthermocycler, at a total reaction volume of $25 \mu \mathrm{l}$ (including $6.5 \mu l$ RNA). Five different master mixes were prepared for each sample (influenza $A$, influenza $B, H 1, H 3$ and internal control). Forty reaction cycles were performed as follows: $45^{\circ} \mathrm{C}$ for $10 \mathrm{sec}, 95^{\circ} \mathrm{C}$ for $10 \mathrm{~min}$ and $72^{\circ} \mathrm{C}$ for $1 \mathrm{~min}$. Primers and probes used in the reactions are shown in (Table 1).

\section{Virus isolation and identification}

Nasal and pharyngeal swabs in virus transport medium were transferred into microtubes, centrifuged at 1200rpm for $5 \mathrm{~min}$. and $125 \mu \mathrm{l}$ of the supernatant was inoculated into confluent and permissive MDCK, which are sensitive to infection by human influenza viruses including $A(H 1 N 1) p d m 09$. The cell culture medium contained Dulbecco's Modified Eagle medium (D-MEM), 10\% fetal calf serum (Gibco), $100 \mathrm{IU} / \mathrm{ml}$ penicillin and $100 \mathrm{mg} / \mathrm{ml}$ streptomycin and $1 \%$ trypsin (Sigma, USA). MDCK cultures were incubated $37^{\circ} \mathrm{C}$ for up to 10 days and were observed daily for the appearance of cytopathic effect (CPE). The Hemagglutination test (HA) was performed on culture supernatants using $0.5 \%$ chicken red blood cells and an HA titer of $1 / 32$ or higher was used for viral strain identification with the Hemagglutination-inhibition method (HAI) as previously described
Table 1 Primers and probes used in real-time RT-PCR.

\begin{tabular}{l} 
Influenza type A \\
A-Fw CTTCTAACCGAGGTCGAAACGTA \\
A-Rv GGTGACAGGATTGGTCTTGTCTTTA \\
A-probe- 5'-Fam -TCAGGCCCCCTCAAAGCCGAG-3' \\
Influenza type B \\
\hline B-Fw ATTGCTGGTTTCTTAGAAGG \\
B-Rv TTGTTTATRGCTTCTTGMGT \\
B-probe 5'-Fam- ATGGGAAGGAATGATTGCAGGT-3' \\
A (H1N1) \\
H1-Fw GAGCTAAGAGAGCAATTGA \\
H1-Rv GTAGATGGATGGTGAATG \\
H1- Probe 5'-Fam -TTGCTGAGCTTTGGGTATGA -3' \\
A (H3N2) \\
H3-Fw AGCAAAGCCTACAGCAA \\
H3-Rv GACCTAAGGGAGGCATAA \\
H3-Probe 5'-Fam-CCGGCACATCATAAGGGTAACA 3'
\end{tabular}

Table 2 Influenza virus genotypes circulating in central Greece during 2012-2014.

\begin{tabular}{cccc|}
\hline $\begin{array}{c}\text { Influenza Season } \\
\begin{array}{c}\text { Samples } \\
\text { examined }\end{array}\end{array}$ & $2012-13$ & $2013-14$ & Total \\
\hline A (H1N1) & 0 & 523 & 865 \\
\hline A (H3N2) & $49(14 \%)$ & $81(16 \%)$ & $81(9 \%)$ \\
\hline B & $31(9 \%)$ & $35(11 \%)$ & $104(12 \%)$ \\
\hline
\end{tabular}

[7]. Antisera for virus identification in the HAl test were provided by the WHO and used according to standard protocol [14].

\section{Nucleotide sequencing}

Purified rt-RT-PCR products were sequenced by an automated sequence analyzer CEQ $^{\mathrm{TM}} 8000$ Genetic Analysis System, Beckman Coulter with Genome Lab ${ }^{\text {TM }}$ Dye Terminator Cycle Sequencing (Quick Start Kit). Sequences obtained were analyzed by the Blast (National Center Biotechnology Information) and Clustal Omega (European Molecular Biology Laboratory) programs and were compared to similarinfluenza virus sequences in Genbank (data not shown).

\section{Results}

During the period 2012-13, 342 respiratory samples were examined at the microbiology laboratory of the University Hospital, Larissa, Greece. Following initial screening with rt RT-PCR assay, 80 samples (23\%) were found positive, of those $14 \%$ were positive to influenza type A ( $\mathrm{H} 3 \mathrm{~N} 2)$ viruses and $9 \%$ to influenza type B viruses. There were no A (H1N1) viruses detected during the same period from the samples examined. In the 2013-14 season 523 samples were examined and 139 (27\%) were found positive by rt RT-PCR. During the 2013-14 season, influenza type $A(H 3 N 2)$ and $A(H 1 N 1)$ and type $B$ viruses were detected and isolated from the positive samples. More specific, of the positive samples of the $2013-14$ season, $98 \%$ tested positive for type $A$ viruses and only $2 \%$ for type B viruses. Influenza A (H1N1) and A (H3N2) viruses were detected in $60 \%$ and $40 \%$ of the positive type A viruses, respectively, (Table 2). There were no mixed infections of influenza $A$ and $B$ detected in the samples examined in this study. 
Analysis of the hemagglutinin antigen of the $A(H 1 N 1)$ and $A(H 3 N 2)$ and $B$ viruses by the $\mathrm{HAl}$ method following virus propagation in MDCK cells revealed relatedness (HAI titer of $>1 / 640$ ) to the WHO influenza vaccine strains of the respective periods, (data not shown). Similarly, comparison of the hemagglutinin nucleotide sequences of $A(H 1 N 1)$ and $A(H 3 N 2)$ viruses with those of reference and vaccine influenza strains revealed homology of 98\%. In all the samples examined during the above mentioned periods there were found no mixed infections. Type A or B. Also, we found $100 \%$ correlation between the rt RT-PCR and cell culture.

\section{Discussion}

Our results indicate that following the global circulation of pandemic A (H1N1) viruses during the 2009-11 period, influenza A (H1N1) virus activity in central Greece was at very low levels during the 2012-13 season as it was not detected in any of the samples examined. This finding is consistent with the epidemiology of $A(H 1 N 1)$ viruses as reported by other countries of the WHO network [8-10]. In comparison to the vaccine strains of the 2012-2013 and later seasons, our A (H1N1) viral isolates were antigenically similar to the $A / C a l i f o r n i a / 7 / 2009$ (H1N1) pdm09 viruses while our $A$ (H3N2) isolates reacted to a high titer against the A/Victoria/361/2011(H3N2)-like viruses, indicating that there was provided adequate immune coverage by the influenza vaccination program during these seasons. Our findings suggest that during the 2012-2014 period, influenza A viruses were the dominant viral type to circulate in different regions of central Greece, showing antigenic and molecular similarity to vaccine-like viruses also in circulation during the same period in different parts of the world [15-17]. This work constitutes a preliminary study on influenza molecular epidemiology in central Greece and further underlines the importance of regular influenza epidemiological and virological surveillance in order to more effectively manage yearly influenza activity.

\section{Acknowledgement and Funding}

This research has been co-financed by the European Union (European Social Fund - ESF) and Greek national funds through the Operational Program "Education and Lifelong Learning" of the National Strategic Reference Framework (NSRF) Research Funding Program: ARCHIMEDES III. Investing in knowledge society through the European Social Fund. 


\section{References}

1 Lamb RA, Krug RM (1996) Orthomyxoviridae: The viruses and their replication in virology (Fields, BN, Knipe, DM, Howley PM., Eds) ipincott-Raven, Philadelphia, 1353-1395.

2 Cox NJ, Subbarao K (1999) Influenza' The Lancet 354: 1277-1282.

3 Gamblin SJ, Skehel JJ (2010) Influenza hemagglutinin and neuraminidase membrane glycoproteins. J Biol Chem 285: 2840328409.

4 Fouchier RA, Munster V, Wallenstein A, Bestebroer TM, Herfst S, et al. (2005) Characterization of a novel influenza A virus hemagglutinin subtype (H16) obtained from black-headed gulls. J Virol 79: 2814-2822.

5 Dawood FS, Jain S, Finelli L, Shaw M, Lindstrom S, et al. (2009) Emergence of a novel swine-origin influenza A (H1N1) virus in humans. N Engl J Med 360: 2605-2615.

6 Thompson WW, Shay DK, Weintraub E (2003) Mortality associated with influenza and respiratory syncytial virus in the United States. JAMA; 289:179-186.

7 Plakokefalos ET, Vontas A, Gramoustianou E, Markoulatos P, Krikelis $V$, et al. (2013) Evolution of hemagluttinin gene in archival influenza A (H3N2) viruses isolated in Southern Greece during 1980-2004. Proceedings of the Scientific Conference 365-367.

8 Melidou A, Gioula G, Exindari M (2015) Genetic analysis of postpandemic 2010-2011 influenza A(H1N1)pdm09 hemagglutinin virus variants that caused mild, severe, and fatal infections in Northern Greece. J Med Virol 87: 57-67.
9 Claas EC, van Milaan AJ, Sprenger MJ, Ruiten-Stuiver M, Arron $\mathrm{Gl}$, et al. (1993) Prospective application of reverse transcriptase polymerase chain reaction for diagnosing influenza infection in respiratory samples from a children's hospital. J Clin Microbiol 31: 2218-2221.

10 CDC protocol of real-time RT-PCR (2009) Emergencies preparedness, response, Pandemic (H1N1) 2009 guidance documents.

11 Runstadler JA, Happ GM, Slemons RD (2005) Using RRT-PCR analysis and virus isolation to determine the prevalence of avian influenza virus infections ducks at Minto Flats State Game Refuge, Alaska Arch Virol 152: 1901-1910.

12 Ellis J, Iturriza M, Allen R (2009) Evaluation of four real-time PCR assays for Detection of influenza $A(H 1 N 1)$ viruses. Euro Surveill 14.

13 Spackman E, Suarez DL (2008) Type a influenza virus detection and quantitation by real-time RT-PCR. Methods Mol Biol 436:19-26.

14 World Health Organization (2011) Manual for the laboratory diagnosis and virological surveillance of influenza.

15 World Health Organization (2012) Weekly Epidemiological Record, 87: 461-476.

16 World Health Organization (2013) Weekly Epidemiological Record 88: 465-476.

17 World Health Organization (2014) Weekly Epidemiological Record 89: $429-440$. 